\section{In memoriam. Dr. Victorino Farga}

\section{In memoriam. Dr Victorino Farga}

\section{Señor Editor:}

Con el fallecimiento del Dr. Victorino Farga desaparece uno de los últimos grandes maestros de la medicina chilena. Nacido en Barcelona en 1927, sufrió los duros años de la Guerra Civil Española (1936-1939) y luego de pasar a pie los Pirineos entró a Francia, donde su padre consiguió ser refugiado chileno y llegar con su familia a Chile en el Winnipeg. Aquí realizó sus estudios de medicina siendo el mejor alumno de su promoción y fue becado a la Cátedra de Medicina del Hospital San Juan de Dios, dirigido por el memorable profesor Armas Cruz. Allí se dedicó a la tuberculosis creando el "Tratamiento de Observación Directa" de los pacientes en forma ambulatoria, lo que permitió darlos de alta de los sanatorios,que luego se transformaron en hospitales, y tener gran éxito en el tratamiento asociado antituberculoso hasta casi erradicar la enfermedad en Chile a través de las "Centrales de Tratamiento Controlado” del Programa Nacional de Tuberculosis del Ministerio de Salud.

El año 1974 debió partir al exilio luego de pasar por varios centros de detención -entre otros Tres Álamosdonde llegó a ser Director Ejecutivo de la International Union Against Tuberculosis (IUAT), con sede en París, desde donde organizó programas de control de esa enfermedad en países de Asia, África y América Latina, para regresar a Chile en 1978 y reincorporarse al Hospital San Juan de Dios y al Hospital del Tórax, donde culminó su carrera científica y profesional después de recibir los máximos honores a los que puede aspirar un médico chileno, incluyendo ser miembro de número de la Academia Chilena de Medicina.

Conocí al Dr. Farga en el Sanatorio El Peral a comienzos de los años 70, donde era Jefe del Servicio de Tisiología, en pleno período de transición al Hospital Dr. Sótero del Río. Allí nos juntábamos semanalmente en reuniones clínicas de pacientes con tuberculosis. En una conversación personal luego de una de esas reuniones, me comentó algo que se me quedó grabado para siempre: "La medicina ha avanzado mucho y hoy podemos resolver la mayor parte de los problemas de salud de los pacientes. Lo que falta y hay que mejorar, es el trato y la cercanía con ellos. Eso no se puede reemplazar y se está perdiendo". Esas palabras tan simples pero profundas están más vigentes que nunca después de varias décadas. Por todo lo que nos entregó a cada uno de nosotros, a Chile y al mundo, rendimos homenaje al maestro sabio, generoso, sencillo y cálido que fue Victorino Farga.

Dr. Fernando Vio del Río ${ }^{1}$ Profesor Titular

Instituto de Nutrición y Tecnología de los Alimentos (INTA). Universidad de Chile. Santiago, Chile. 